Journal of

Materials

Chemistry

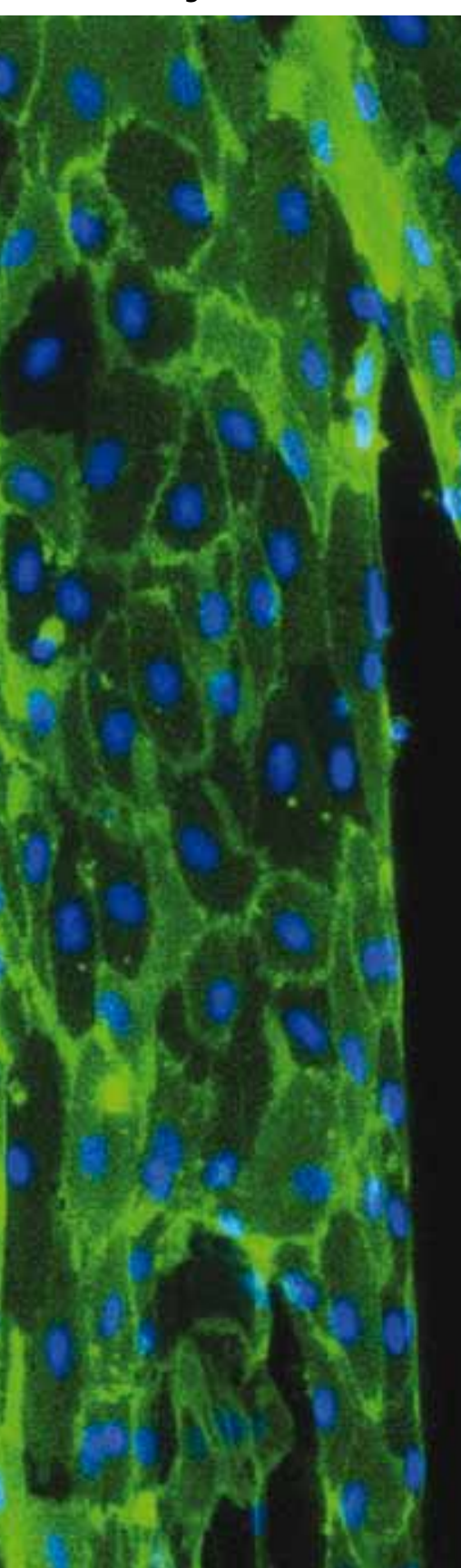

\section{PAPER}

C. James Kirkpatrick et al.

Surface-modified 3D starch-based

scaffold for improved endothelialization an alternative approach towards for bone tissue engineering

\section{FEATURE ARTICLE}

Bruno Chaudret et al.

Organometallic chemistry: metal oxide nanoparticles

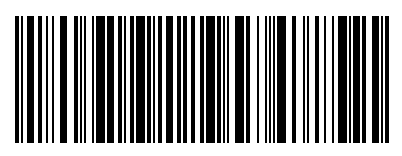

0959-9428(2009)19:24;1-S 


\title{
Surface-modified 3D starch-based scaffold for improved endothelialization for bone tissue engineering
}

\author{
M. I. Santos, ${ }^{a b c}$ I. Pashkuleva, ${ }^{a b}$ C. M. Alves, ${ }^{a b}$ M. E. Gomes, ${ }^{a b}$ S. Fuchs, ${ }^{c}$ R. E. Unger, ${ }^{c}$ R. L. Reis ${ }^{a b}$ \\ and C. J. Kirkpatrick *c
}

\author{
Received 28th October 2008, Accepted 5th March 2009 \\ First published as an Advance Article on the web 31st March 2009 \\ DOI: $10.1039 / b 819089 e$
}

Providing adequate vascularization is one of the main hurdles to the widespread clinical application of bone tissue engineering approaches. Due to their unique role in blood vessel formation, endothelial cells (EC) play a key role in the establishment of successful vascularization strategies. However, currently available polymeric materials do not generally support EC growth without coating with adhesive proteins. In this work we present argon plasma treatment as a suitable method to render the surface of a 3D starch-based scaffold compatible for ECs, this way obviating the need for protein precoating. To this end we studied the effect of plasma modification on surface properties, protein adsorption and ultimately on several aspects regarding EC behaviour. Characterization of surface properties revealed increased surface roughness and change in topography, while at the chemical level a higher oxygen content was demonstrated. The increased surface roughness of the material, together with the changed surface chemistry modulated protein adsorption as indicated by the different adsorption profile observed for vitronectin. In vitro studies showed that human umbilical vein ECs (HUVECs) seeded on plasma-modified scaffolds adhered, remained viable, proliferated, and maintained the typical cobblestone morphology, as observed for positive controls (scaffold pre-coated with adhesive proteins). Furthermore, genotypic expression of endothelial markers was maintained and neighbouring cells expressed PECAM-1 at the single-cell-level. These results indicate that Ar plasma modification is an effective methodology with potential to be incorporated in biomaterial strategies to promote the formation of vascularized engineered bone.

\section{Introduction}

During its 15 years of existence the tissue engineering field has evolved greatly and important milestones have been achieved. ${ }^{1}$ However, despite the major advances this field has brought, the lack of vascular supply remains the holy grail and the main hurdle to the clinical application of large constructs. When in vitro engineered cellular constructs are transferred in vivo, they have to rely on processes, such as interstitial fluid diffusion and blood perfusion to cover their metabolic demands. ${ }^{2}$ Theoretical modeling studies predict hypoxia and central necrosis in almost any graft site with a diffusion distance of more than 500 to 1000 $\mu \mathrm{m} .{ }^{3}$ Therefore, a successful engineered-construct must be supported by a dense capillary network connected to the microcirculation at the implantation site, supplying perfusion for adequate oxygenation and nutrition, as well as removal of waste products from the corresponding tissues.

\footnotetext{
a3B's Research Group - Biomaterials, Biodegradables and Biomimetics, University of Minho, Headquarters of the European Institute of Excellence on Tissue Engineering and Regenerative Medicine, AvePark, 4806-909 Taipas, Guimarães, Portugal

${ }^{b} I B B$ - Institute for Biotechnology and Bioengineering, PT Government Associated Laboratory, Braga, Portugal

'Institute of Pathology, Johannes Gutenberg University Mainz, Langenbeckstr. 1, Mainz, 55101, Germany. E-mail: kirkpatrick@ ukmainz.de; Fax: +49 613117477301; Tel: +496131 177301
}

In the particular case of bone, a functional vascular network is more than just simple conduits that ensure cellular metabolic requirements. Its importance is already manifested in bone ontogeny, where angiogenesis precedes osteogenesis and continues during bone process repair. ${ }^{4}$ Furthermore, initial vascularization may be essential for enhanced engraftment and prevention of infections. ${ }^{2}$ For these reasons, induction of vascularization is an integral element of any successful bone tissue engineering concept. Several strategies have been proposed to accelerate vascularization in engineered bone. Hybrid approaches, combining tissue engineering with microvascular surgical techniques such as free bone flap ${ }^{5}$ and pedicle bone flap transplantation, ${ }^{6}$ have been described. Nevertheless, these methods are associated with several major drawbacks such as the need for a donor site, creation of a soft-tissue donor-site defect and the consequent patient inconvenience in the clinical setting., 5 The localized or systemic application of angiogenic growth factors has also been one of the most popular strategies. ${ }^{8}$ Delivery systems releasing a single angiogenic growth factor ${ }^{9}$ have been upgraded into multi-phasic delivery systems, ${ }^{10}$ able to promote the formation of more stable vessels. However, these systems can only be regarded as an adjuvant of vascularization orchestration. As ECs are the main cellular mediator of neovascular growth several approaches for vascularized engineeredbone involving this cell type have been explored. Strategies involving bulk culturing of mature ECs, ${ }^{11}$ progenitor cells ${ }^{12}$ or ECs combined with other cell types such as osteoblasts ${ }^{13}$ can be 
found in the literature. It is expected that in the in vivo environment ECs migrate out from the tissue-engineered construct into the implantation site, form networks of capillaries and gain access to the recipient's circulation. ${ }^{2,7}$ Hence, whether relying on an extrinsic or intrinsic blood supply, the adopted neovascularization approach will always have, directly or indirectly, ECs as target cell type. Therefore, it is of ultimate importance that the $3 \mathrm{D}$ construct is compatible with this cell type.

It is rare that a biomaterial with adequate bulk properties also possesses the surface characteristics suitable for clinical application $^{14}$ and this is particularly true for ECs because most of the proposed polymeric substrates do not support their adhesion and growth. A common approach is to fabricate biomaterials with appropriate bulk properties and to modify those by specific treatments resulting in enhanced surface properties. ${ }^{15}$ Surface modification techniques for three-dimensional (3D) polymeric structures include different wet chemical treatments such as grafting, attaching cell-recognizing ligands or more aggressive methods such as soaking in oxidative or hydrolytic baths. However, a lack of reactive groups on the polymer backbones and/or interactions between the solvents and the modified materials, also leading to bulk modification, are very often obstacles to the use of these methods. Hence, some research has been focused on coating of scaffolds with extracellular matrix proteins in order to increase cell adhesion to the surface. ${ }^{16,17}$ Although this approach overcomes the difficulties related with the wet-based treatments, protein adsorption is a difficult process to control and its stability with time is problematic. ${ }^{18}$ Plasma surface modification has only recently been considered as an alternative route to enhance the surface biocompatibility of 3D polymer-based structures. ${ }^{19,20}$ The difficulties in modification of scaffolds by plasma are enhanced by the requirement for highly porous and interconnected samples. Therefore, application of different plasma surface modification has been limited to various polymer membranes and 2D bulk structures.

In this work, fiber-mesh scaffolds made from a blend of starch with polycaprolactone (SPCL) that were previously proposed for bone engineering scaffolding, ${ }^{21-24}$ have been modified by means of argon (Ar) plasma treatment. This method was applied to tailor the surface of SPCL scaffold to promote EC adhesion and proliferation, and thus obviate the need for protein pre-coating. To our knowledge this is the first report on an efficient plasma surface modification of a 3D natural-based construct for tissue engineering applications. The effect of plasma treatment at the surface properties level and its influence on the adsorption of adhesive proteins were assessed. Furthermore, the ultimate benefits of plasma-modified SPCL fiber-mesh scaffolds were evaluated by assessing EC biological responses, namely adhesion, proliferation profile and genotypical/phenotypical expression of endothelial markers.

\section{Materials and methods}

\subsection{Scaffolds}

Scaffolds produced from a blend of starch with polycaprolactone (SPCL, 30/70 wt \%) were used for this study. SPCL fiber-mesh scaffolds were obtained by a fiber-bonding process consisting of spinning, cutting and sintering melt-spun fibers, as previously described. ${ }^{21,22,25}$ The samples were cut into discs with $8 \mathrm{~mm}$ diameter and $2 \mathrm{~mm}$ height and sterilized by ethylene oxide.

\subsection{Plasma surface modification}

The surface treatment was performed using a plasma reactor PlasmaPrep $_{5}$ (Gala Instrument $\mathrm{GmbH}$, Germany) with a fully automated process control. Argon was used as a working gas and the pressure in the reactor was controlled $(0.18$ mbar $)$ by adjusting the flow rate. Prior to treatment, the chamber was purged with argon five times. A radio frequency source (13.56 $\mathrm{MHz}$ ) was used and a power of $30 \mathrm{~W}$ was applied for $15 \mathrm{~min}$. The samples were kept at air atmosphere after being removed from the reactor.

\subsection{Surface characterization and protein adsorption}

Scanning electron microscopy (SEM). The surface morphology of SPCL fibers was analysed by a Leica Cambridge S360 scanning electron microscope (SEM) before and after plasma treatment. The samples were previously sputter-coated with gold in an ion sputter chamber (JEOL JFC 1100). Microphotographs at the surface were taken at various magnifications.

Optical profiler analysis. Optical profilometry is a non-contact method which allows roughness analysis of 3D structures with high resolution from subnanometer to millimetre step-height. In this study an optical profiler Wyko NT 3300 from Veeco Instruments Inc. was used. The measurements were performed in Vertical Scanning Interferometry (VSI) mode and an area of 2 $\mathrm{mm}$ was analysed with a vertical resolution of $3 \mathrm{~nm}$.

X-Ray photoelectron spectroscopy (XPS). XPS was used to determine the elemental surface composition of treated and untreated samples. The analysis was carried out using the instrument VG Escalab 250 iXL (VG Scientific, UK). The measurements were performed with monochromatic Al-K $\alpha$ radiation $(h \nu=1486.6 \mathrm{eV})$ in a constant analyzer energy mode (CAE) with $100 \mathrm{eV}$ pass energy for survey spectra and $20 \mathrm{eV}$ pass energy for high-resolution spectra. Photoelectrons were collected from a take-off angle of $90^{\circ}$ relative to the sample surface. Charge referencing was adjusted by setting the lower binding energy $\mathrm{C} 1 s$ hydrocarbon $\left(\mathrm{CH}_{x}\right)$ peak at $285.0 \mathrm{eV}$. Surface elemental composition was determined by standard Scofield photoemission cross sections. The identification of the chemical functional groups was obtained from the high-resolution peak analysis of $\mathrm{C} 1 s$ envelopes by XPSPEAK 4.1 software.

Time-of-flight secondary ion mass spectrometry (TOF-SIMS). Detailed quantitative analysis of the surface composition before and after plasma modification was obtained by TOF-SIMS. The mass spectra of the samples were recorded on a TOF-SIMS IV instrument from Ion-TOF GmbH Germany. The samples were bombarded with a pulsed bismuth ion beam $(25 \mathrm{keV})$ at $45^{\circ}$ incidence over an area with size $100 \mathrm{~mm}^{2}$. The generated secondary ions were extracted with a $10 \mathrm{kV}$ voltage and their time of flight from the sample to the detector was measured in a reflection mass spectrometer. 
Contact angle measurements. Surface wettability was evaluated by static contact angle measurements on 2D samples prepared by a procedure similar to the one used for the scaffolds, i.e. by polymer melting with subsequent injection into a mould. Prior to measurements, the samples were plasma modified at the same conditions used for the scaffolds. The values were obtained by a sessile drop method using a contact angle meter OCA15+ with a high-performance image processing system from DataPhysics Instruments, Germany. The used liquid $\left(\mathrm{H}_{2} \mathrm{O}, 1 \mathrm{~mL}\right.$, HPLC grade) was added by a motor driven syringe at room temperature. Five samples of each material were used and six measurements per sample were carried out. The normality of the data was checked by applying the Shapiro-Wilk W-test. Since all the samples followed a normal distribution, Student's $t$-tests for independent samples were performed to test differences. Throughout the following discussion differences were considered significant if $p<0.05$, and highly significant if $p<0.01$. The statistical analysis was performed with the package Statistica 6.0 (StatSoft, USA).

Protein adsorption: Immunolabelling and confocal laser scanning microscopy (CLSM). The effect of plasma treatment on the adsorption of fibronectin (Fn) and vitronectin (Vn) from the cell culture media was investigated using CLSM in combination with fluorescent immunolabelling methodology. The protein system used in this study was a multi-protein solution of $20 \%(\mathrm{v} / \mathrm{v})$ of fetal calf serum (Sigma, Germany) in M199 medium (Sigma, Germany). Untreated and plasma treated SPCL scaffolds were immersed in this solution and incubated for $1 \mathrm{~h}$ at $37^{\circ} \mathrm{C}$. Samples immersed in phosphate buffered saline solution (PBS) were used as blanks. Then, samples were fixed in a $2.5 \%$ formalin solution for $5 \mathrm{~min}$ and washed with PBS solution. Afterwards, samples were incubated with primary antibody mouse anti-human fibronectin with calf cross-reactivity ( $1: 50$, Sigma, Germany) or mouse antibovine anti-vitronectin ( $1: 50$, Santa Cruz, USA). After washing with PBS, materials were incubated with goat anti-mouse Alexa Fluor 488 secondary antibody (Invitrogen, USA), for $1 \mathrm{~h}$ at RT. Labelled samples were analysed by CLSM (Olimpus IX81).

\subsection{Cell culture and scaffold seeding}

Primary endothelial cells (ECs) derived from the umbilical cord vein (HUVECs) were used for cell culture studies. The cells were isolated from the umbilical vein by collagenase solution. Further details about the procedure can be found elsewhere. ${ }^{26}$ HUVECs were cultured in M199 medium supplemented with 20\% fetal calf serum, $1 \%$ penicillin/streptomycin, $25 \mu \mathrm{g} \mathrm{mL} \mathrm{m}^{-1}$ endothelial cell growth supplement (BD Bioscience, USA) and $2 \mathrm{mM}$ Glutamax I (Gibco, Germany). Cells were cultured in culture flask previously coated with $0.2 \%$ gelatine (Sigma, Germany).

Prior to cell seeding SPCL fiber-mesh scaffolds were soaked overnight in culture medium without serum. Untreated scaffolds pre-coated with $10 \mu \mathrm{g} \mathrm{mL}^{-1}$ fibronectin in PBS (Roche, Germany) for $1 \mathrm{~h}$ at $37{ }^{\circ} \mathrm{C}$ were used as positive control since this is a standard procedure to improve ECs adhesion to a certain substrate. As negative control, non-coated untreated scaffolds were used. Plasma-modified SPCL fiber-mesh scaffolds were also not coated with any protein. Confluent HUVECs were trypsinized and a suspension of $2 \times 10^{5}$ cells was added per scaffold.
The samples were incubated under standard culture conditions $\left(37^{\circ} \mathrm{C}, 5 \% \mathrm{CO}_{2}\right)$ for up to 7 days.

\subsection{Characterization of cell viability, growth and morphology}

Cell growth and viability were assessed by staining with the fluorochrome dye calcein-AM and samples were visualized by CLSM. HUVECs were cultured for $4 \mathrm{~h}, 3$ days and 7 days on the three materials studied: (i) Ar plasma-modified SPCL fiber-mesh scaffold; (ii) positive control (untreated and fibronectin-coated scaffold); and (iii) negative control (untreated and non-coated scaffold). After each time point, the samples were incubated in culture medium with $0.1 \mu \mathrm{M}$ calcein-AM (Invitrogen, USA) for 10 min under standard culture conditions. For CLSM (Leica TCS NT), and samples were prepared in mounting medium (Natutec, Germany). SEM was used to evaluate cellular morphology. Thus, after 7 days of culture samples were fixed with $2 \%$ glutaraldehyde in $0.1 \mathrm{M}$ sodium cacodylate buffer for 30 min and postfixed in $1 \%$ osmium tetroxide for $1 \mathrm{~h}$. Subsequently, samples were dehydrated with increasing ethanol concentrations, dried with hexamethyldisilasane and sputter coated with gold.

\subsection{Cell proliferation assay}

The DNA content in the scaffolds lysate was determined using the fluorescent picoGreen dsDNA quantification assay (Invitrogen, USA). The samples were thawed at room temperature (RT) and sonicated for $15 \mathrm{~min}$. A detailed description of the assay is published elsewhere. ${ }^{27}$ The number of cells was calculated by correlation with the DNA content of a known number of ECs. Triplicates were prepared for all materials and results were presented as means \pm standard deviations. All the values were analysed by a two-tailed Student's $t$-test. Throughout the following discussion, the differences were considered significant if $p<0.05$.

\subsection{Gene and protein expression}

The expression of markers related with ECs and angiogenesis, namely PECAM-1 (CD31), VEGF-R1 and VE-cadherin, was

Table 1 Genes under evaluation, primers and PCR conditions

\begin{tabular}{|c|c|c|c|}
\hline $\begin{array}{l}\text { Name of gene } \\
\text { (GenBank } \\
\text { accession no.) }\end{array}$ & $\begin{array}{l}\text { Product } \\
\text { size/bp }\end{array}$ & $\begin{array}{l}\text { Annealing } \\
\text { temperature } /{ }^{\circ} \mathrm{C}\end{array}$ & $\begin{array}{l}\text { Primer pair } \\
\text { sequences }\end{array}$ \\
\hline $\begin{array}{l}\beta \text {-actin } \\
\quad(\mathrm{AB} 004047)\end{array}$ & 574 & 65 & $\begin{array}{l}\text { 5'AGCATTTGCGG } \\
\text { TGGACGATGGAG-3' } \\
\text { 5'-GACCTGACTGACT } \\
\text { ACCTCATGA-3' }\end{array}$ \\
\hline PECAM-1 & 280 & 57 & $\begin{array}{l}5^{\prime}-\text { CAACAGACATGG } \\
\text { CAACAAGG-3' } \\
\text { 5'- TTCTGGATGGTG }^{\prime} \\
\text { AAGTTG GC-3' }\end{array}$ \\
\hline VE-cadherin & 452 & 57 & $\begin{array}{r}5^{\prime} \text {-GCTGAAGGAAAA } \\
\text { CCAGAAGAAGC-3' } \\
5^{\prime} \text {-TCGTGATTATCCG } \\
\text { TGAGGGTAAAG-3' }\end{array}$ \\
\hline VEGF-R1 & 665 & 55 & $\begin{array}{c}\text { 5'-TCTCCTTAGGTG } \\
\text { GGTCTCC-3' } \\
\text { 5'-CAGCTCAGCG } \\
\text { TGGTCGTAG-3' }\end{array}$ \\
\hline
\end{tabular}


assessed at the mRNA level by semi-quantitative polymerase chain reaction (PCR). Total RNA was extracted from HUVECs cultured for 7 days on Ar plasma-modified SPCL scaffold, on the positive control and on 2D tissue culture polystyrene (TCPs), using the RNeasy Micro Kit (Qiagen, Germany). Equal amounts of RNA $(1 \mu \mathrm{g})$, measured by the NanoDrop microspectrophotometer, were reverse transcribed into cDNA (Omniscript RT Kit, Qiagen, Germany). Afterwards, using gene-specific primer sets (Table 1) the genes of interest were amplified by PCR with Taq DNA polymerase Kit (Qiagen). The procedure for all the genes included 35 cycles, consisting of an initial stage of $2 \mathrm{~min}$ of denaturation at $94{ }^{\circ} \mathrm{C}$, followed by $30 \mathrm{~s}$ of annealing (Table 1), $30 \mathrm{~s}$ of chain elongation at $72{ }^{\circ} \mathrm{C}$ and a final $10 \mathrm{~min}$ extension at $72{ }^{\circ} \mathrm{C}$. Amplification products were separated by electrophoresis on an agarose gel $(0.8 \%)$ and stained with ethidium bromide. $\beta$ actin was selected as the housekeeping gene.

The expression of PECAM-1, a major endothelial hallmark, was evaluated at the cell-cell level by immunocytochemistry. Hence, after 7 days of culture, the samples were fixed with a solution of $2 \%$ paraformaldehyde for $30 \mathrm{~min}$ and washed with PBS. Then, the cells were permeabilized with $0.1 \%$ Triton for 5 min and incubated with mouse anti-human PECAM-1 (1 : 50, Dako, Denmark) for $1 \mathrm{~h}$. After PBS washing, the secondary antibody goat anti-mouse Alexa Fluor 488 (Invitrogen, USA) was added and incubated for $1 \mathrm{~h}$. Nuclei were counterstained with $1 \mu \mathrm{g} \mathrm{mL}^{-1}$ Hoechst in PBS for $5 \mathrm{~min}$. For CLSM observation SPCL fiber-mesh scaffolds were covered with mounting medium. All immunostaining procedures were performed at RT.

\section{Results}

\subsection{Physical and chemical characterization of Ar plasma modified SPCL fiber-mesh scaffolds}

During the contact of plasma with the biomaterial surface different physical and chemical processes occur. These processes can provoke changes in surface morphology and composition, which in turn can affect protein and cell behaviour on the modified material. Untreated materials presented a smooth surface with minor irregularities (Fig. 1a and 2a), typically observed for
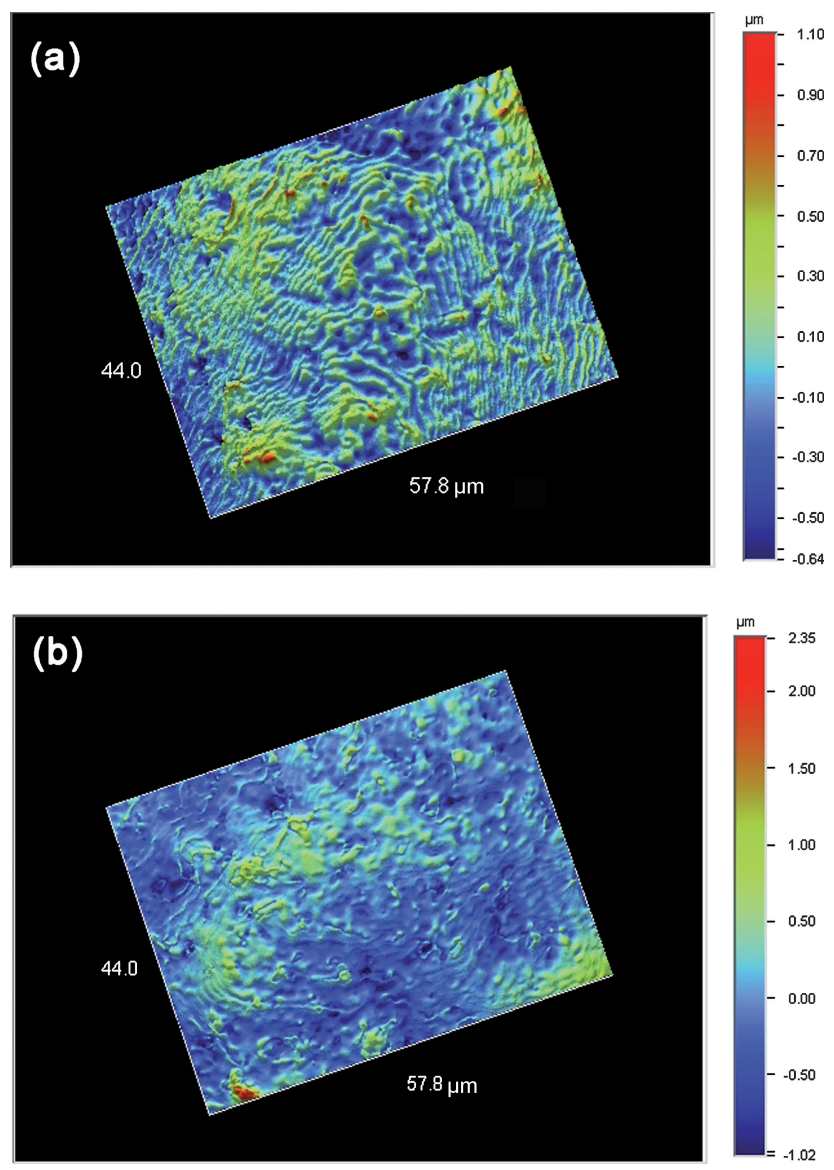

Fig. 2 Optical profiler micrographs for SPCL fibers before (a) and after (b) surface modification by Ar plasma (Mode: VSI, Mag: 107×). (a) CONTROL
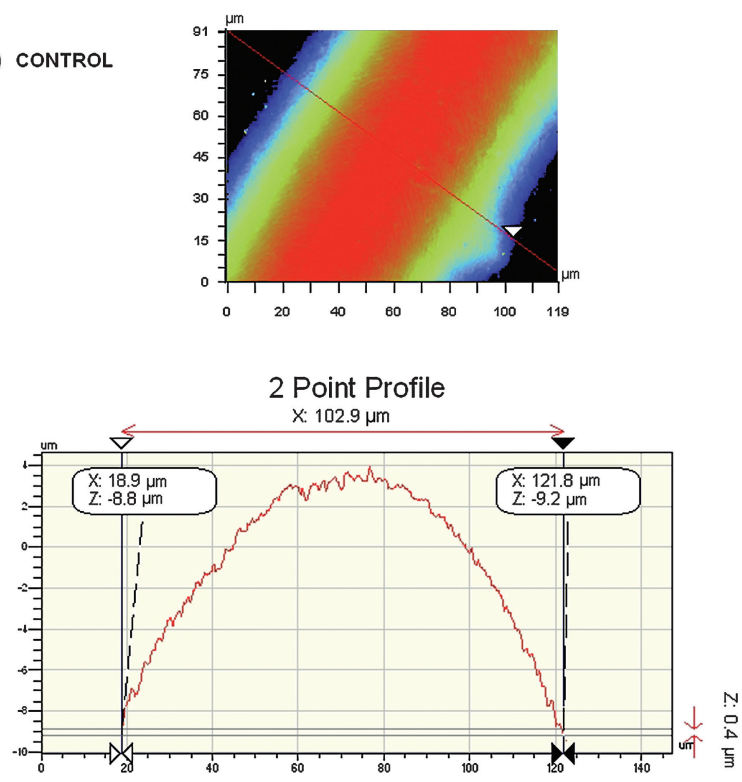

(b) PLASMA
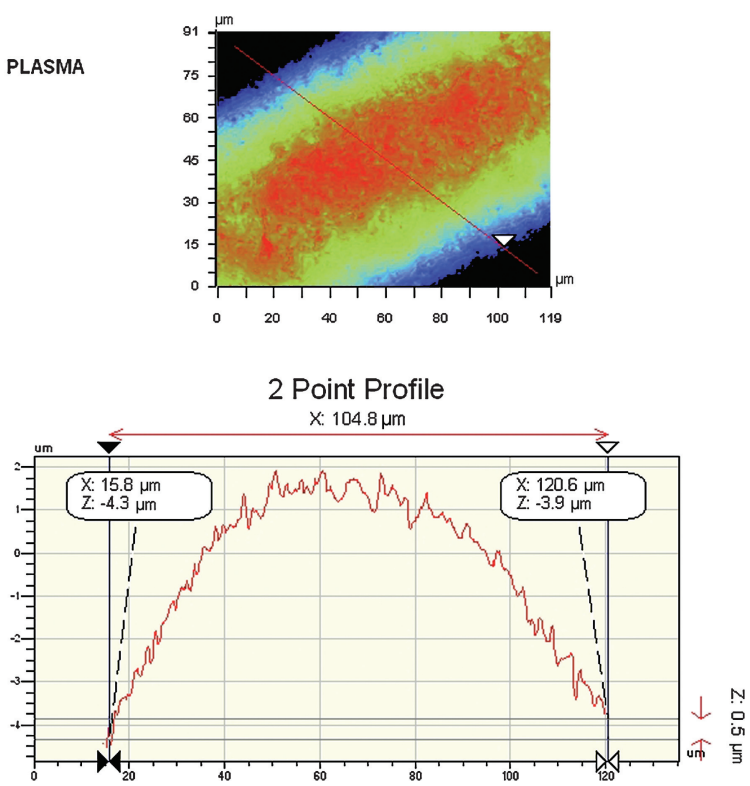

Fig. 1 Two-points line profile analysis for untreated (a) and plasma modified (b) SPCL. 
melt-processed polymers. Although the SEM analysis did not show different morphology or surface texture after the applied plasma treatment (pictures not shown) the results from optical profiler demonstrated (Fig. $1 \mathrm{~b}$ and $2 \mathrm{~b}$ ) a strong increase of the surface roughness for the modified samples. An average roughness of $\mathrm{Ra}=144.5 \pm 6.5 \mathrm{~nm}$ was measured for the untreated samples, while this value was almost double for the modified ones $(\mathrm{Ra}=236.5 \pm 18.5 \mathrm{~nm})$. Moreover, not only roughness but also a topography change was observed for the modified samples and the characteristic laminated structure of untreated samples was markedly reduced (Fig. 2).

Table 2 Calculated atomic concentrations of the building elements (carbon and oxygen) of the studied materials

\begin{tabular}{llll}
\hline Material & $\% \mathrm{C}$ & $\% \mathrm{O}$ & $\mathrm{C}:$ O ratio \\
\hline Theoretical PCL & 75.0 & 25.0 & 3.00 \\
Theoretical SPCL & 68.9 & 31.1 & 2.20 \\
Untreated SPCL scaffolds & 77.0 & 23.0 & 3.35 \\
Plasma-modified SPCL scaffolds & 72.2 & 27.8 & 2.60 \\
\hline
\end{tabular}
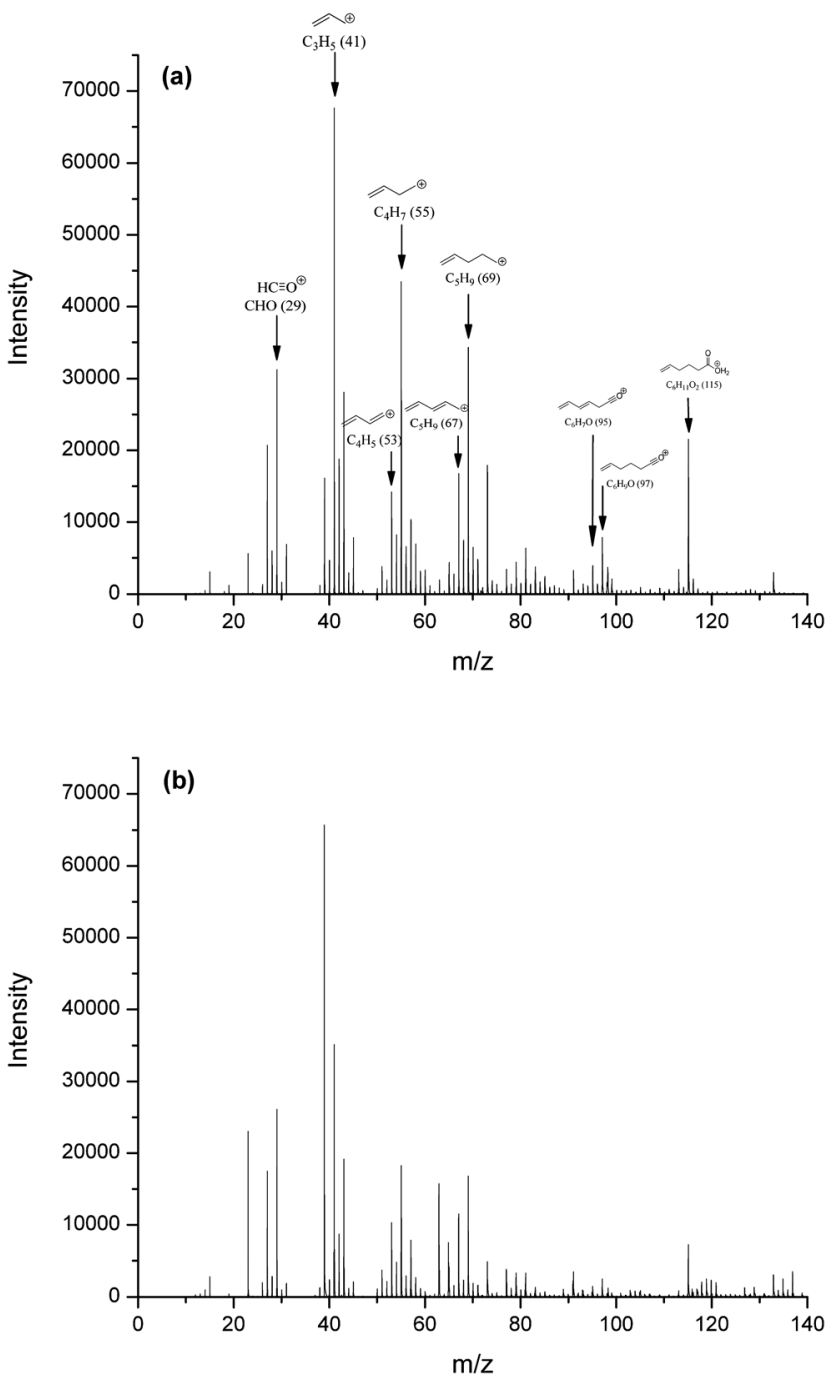

Fig. 3 Positive ion TOF-SIMS spectra of SPCL fiber mesh before (a) and after (b) plasma modification. The PCL peaks are marked.
On the other hand, the surface chemistry was also affected by the applied treatment and significantly higher oxygen content was measured for the modified surface compared to the untreated one (Table 2). The measured $\mathrm{C}$ : $\mathrm{O}$ ratio together with the TOF-SIMS spectrum (Fig. 3a) of the untreated material, shows predominant presence of the synthetic component (PCL) on the surface. Prominent peaks characteristic for the low mass hydrocarbon fragments derived from the linear back bone of $\mathrm{PCL}^{28}$ were detected at $m / z 41,55,69,97$ as well as the monomer $(\mathrm{M}+\mathrm{H})^{+}$at $m / z$ 115. The changes induced by the applied treatment were confirmed by SIMS and less intensive peaks were detected in the positive mass spectrum of modified samples (Fig. 3b). The decrease of these peak intensities for the treated material reflects the attack of the aliphatic sites and the subsequent loss/modification of these groups. The change in the general appearance of the negative mass spectra (Fig. 4) as a result of the treatment is typical ${ }^{29}$ for plasma-treated polymers. The original polymer gives rise to a limited number of intense peaks (Fig. 4a), referring to structural ions while plasma treatment produces complex patterns with an intense peak on almost
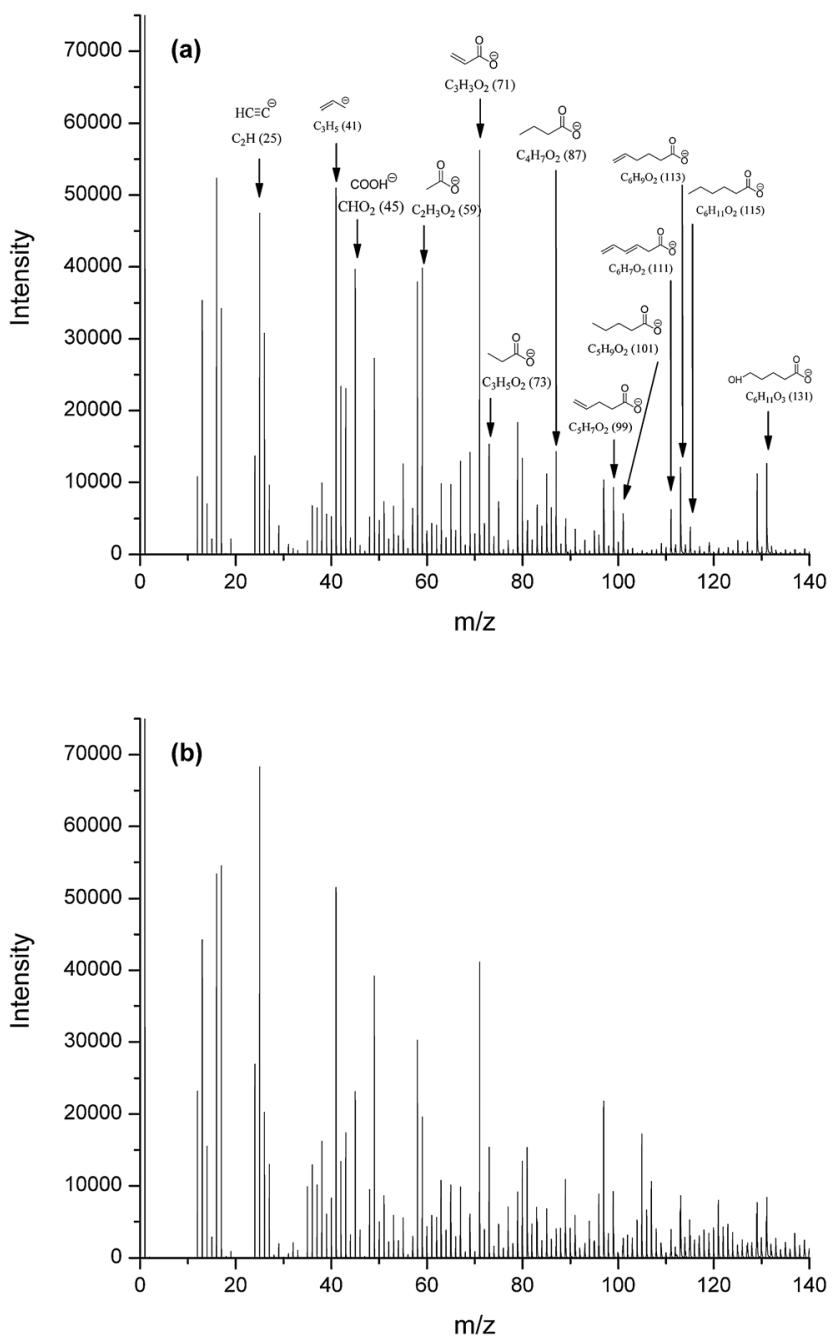

Fig. 4 Negative ion TOF-SIMS spectra of SPCL fiber mesh before (a) and after (b) plasma modification. Characteristic PCL peaks are marked. 
every $m / z$ (Fig. 4b), although the signal-to-noise ratio of individual peaks remains good.

The contact angle values did not show any significant changes in the hydrophilicity of the studied materials. The value of 83.56 \pm 5.34 measured for untreated material was almost the same as that $(81.76 \pm 2.09)$ measured after the applied treatment by plasma. However, it must be noticed that because of the changes in the surface roughness the effect of Cassie ${ }^{30}$ must be present and influences the measured values, especially those after modification.

\subsection{Protein adsorption on treated and untreated SPCL fiber- mesh scaffolds}

Two different adhesive proteins, Fn and Vn, were taken for the studied materials. Fn was chosen for this study because it is commonly used in a standard procedure, applied to improve the adhesion of ECs. Vn is known for its ability to modulate HUVEC spreading and migration. Moreover, a previous study ${ }^{31}$ on 2-dimensional starch-based materials has shown higher adsorption affinity of Vn than Fn or albumin using unitary or complex protein solutions. The micrographs presented on Fig. 5 confirmed the results obtained for 2D samples and higher staining intensities for $\mathrm{Vn}$ can be observed in comparison with those for Fn. Homogeneous protein distribution was similar for both Fn-labelled untreated (Fig. 5a) and treated (Fig. 5b) samples. In contrast, different protein distribution patterns were observed for Vn adsorbed onto non-treated (Fig. 5c) and plasmamodified scaffolds (Fig. 5d). In the latter case, vitronectin presented a heterogeneous distribution on the SPCL fiber surface, with foci of high fluorescent signal on the Ar plasma-treated scaffolds.
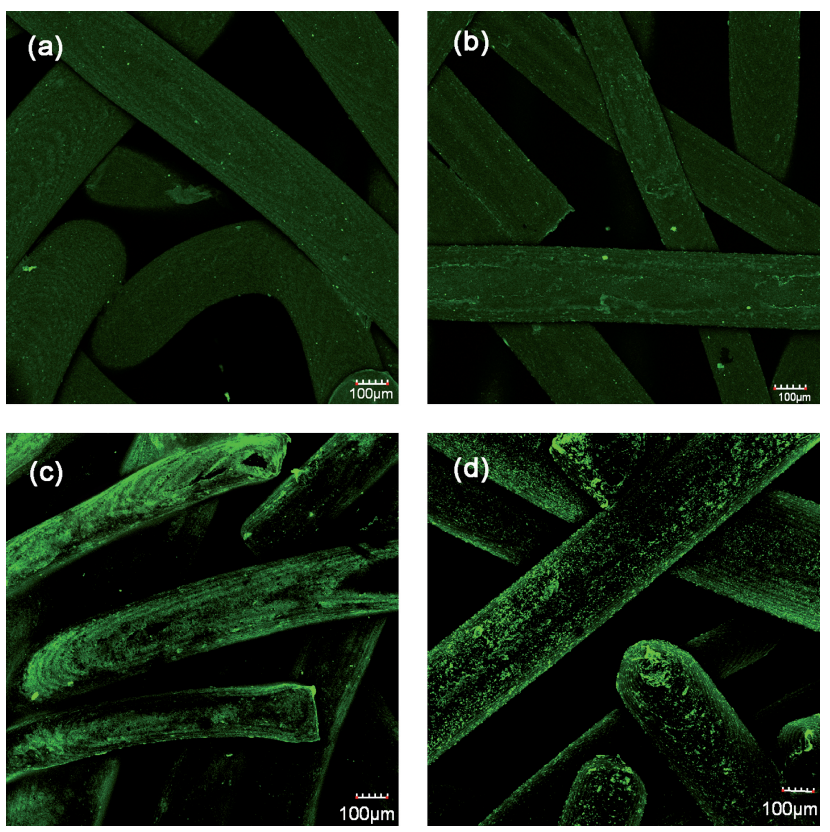

Fig. 5 Untreated (a, c) and plasma-modified (b, d) SPCL fiber meshes immunolabeled for Fn (a-b) and Vn (c-d) after $1 \mathrm{~h}$ immersion in culture medium supplemented with $20 \%$ serum. Note the markedly increased adsorption of Vn compared to Fn.

\subsection{Influence of Ar plasma treatment on cell adhesion, viability} and morphology

Viable ECs were detected on the surface of Ar plasma-modified scaffolds after 4 hours of cell seeding (Fig. 6a). The cells were homogeneously distributed on the scaffold and presented a morphology that reflects an early stage of attachment. On the positive control, i.e., untreated scaffolds pre-coated with fibronectin, viable ECs had also adhered on the surface and the cells exhibited a well-developed spread morphology (Fig. 6b). In contrast, only a few cells exhibiting a rounded-up morphology were observed on the negative control (Fig. 6c). After 7 days of culture, ECs formed a complete monolayer on the surface of the plasma-modified scaffolds, as well as on the positive control (Fig. 6d and 6e). In addition, the morphological differences observed for these two samples at the earlier time points vanished after 7 days of culture. On the other hand, on the negative control, only a few cells were detectable on the scaffold surface (Fig. 6f). Fig. 7 reveals further details of EC morphology on the plasma-modified scaffold and on the positive control after 7 days of culture. ECs exhibited the typical flattened and well-spread morphology in both samples. Moreover, the intimate contact established between neighbouring cells led to a compact and
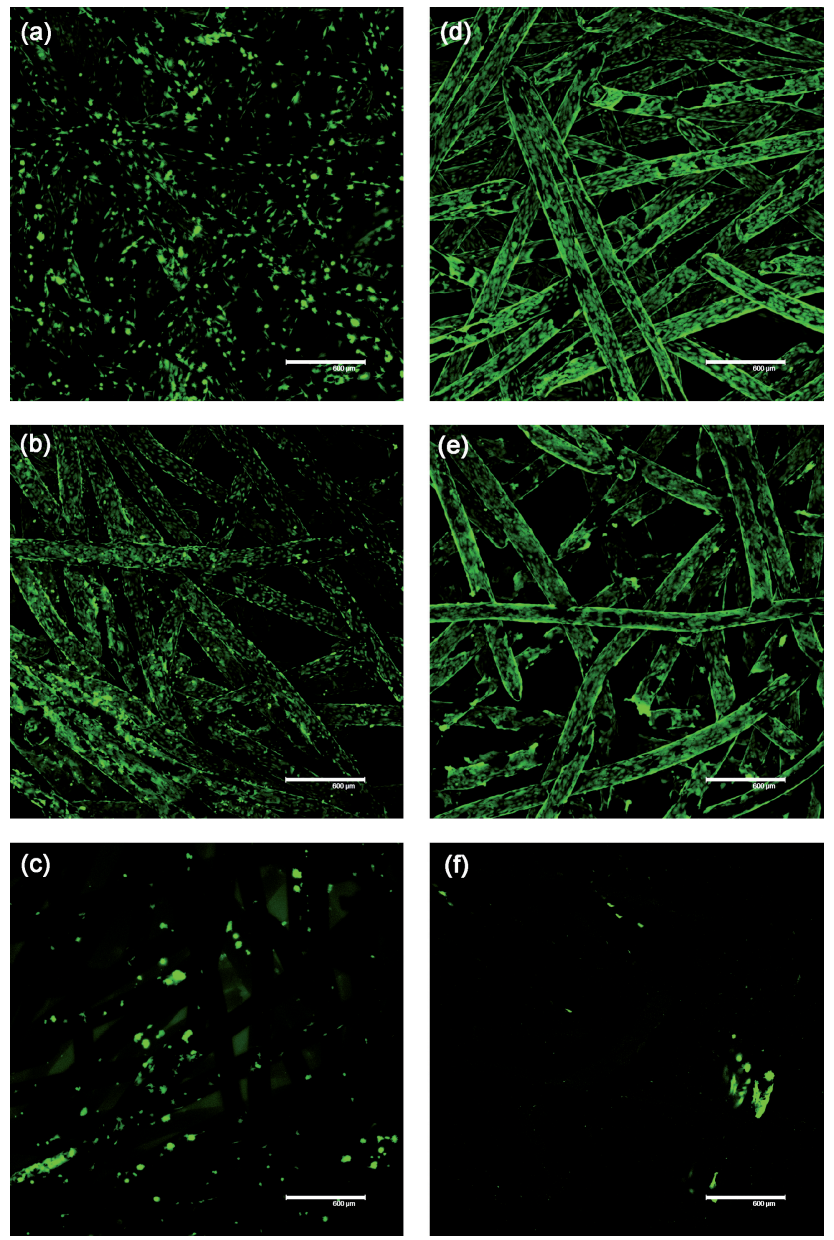

Fig. 6 Calcein-AM viability assay of HUVEC grown on plasmamodified (a, d), Fn-coated (b, e) and untreated (c, f) scaffolds for $4 \mathrm{~h}$ (left column) and 7 days (right column). The value of the scale bars is $600 \mu \mathrm{m}$. 

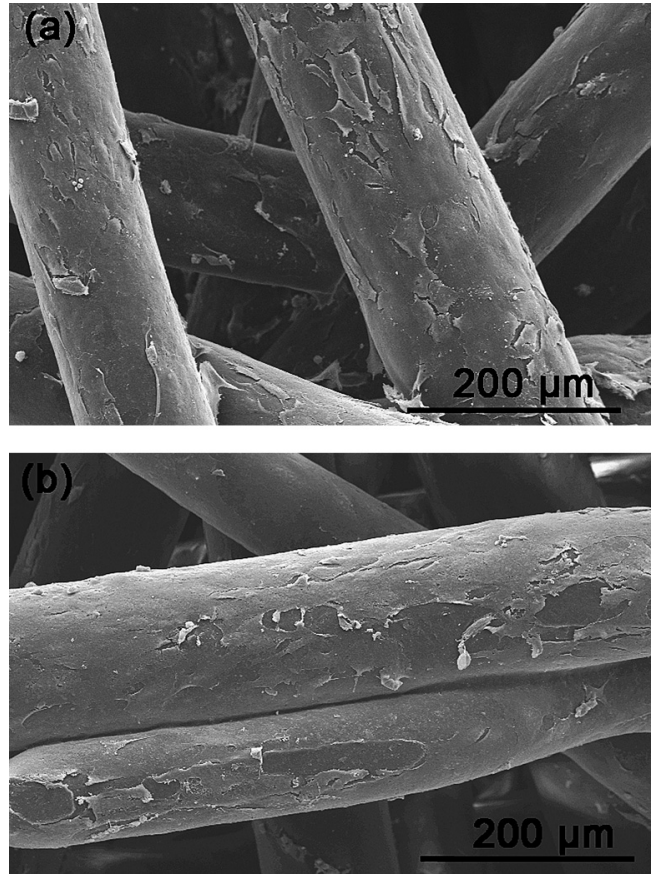

Fig. 7 SEM micrographs of HUVEC grown on plasma-modified scaffolds (a) and on the positive (fibronectin-coated scaffolds) control (b) for 7 days.

uniform cell distribution that covered the individual fibers of the scaffolds.

\subsection{EC proliferation profile on the SPCL fiber mesh scaffolds}

DNA quantification (Fig. 8) showed that HUVECs were able to proliferate when they were cultured on plasma-modified or fibronectin-coated fiber meshes. From day 3 to 7 increased cell proliferation was observed for these two materials and this difference was significant for the plasma-modified material. On the contrary, the negative control sustained the growth of very few cells, and after 7 days of culture this value dropped below the method's detection limit. It must be noted that the highest number of cells was observed on the plasma-modified scaffolds. This pattern was more apparent after longer culture times when

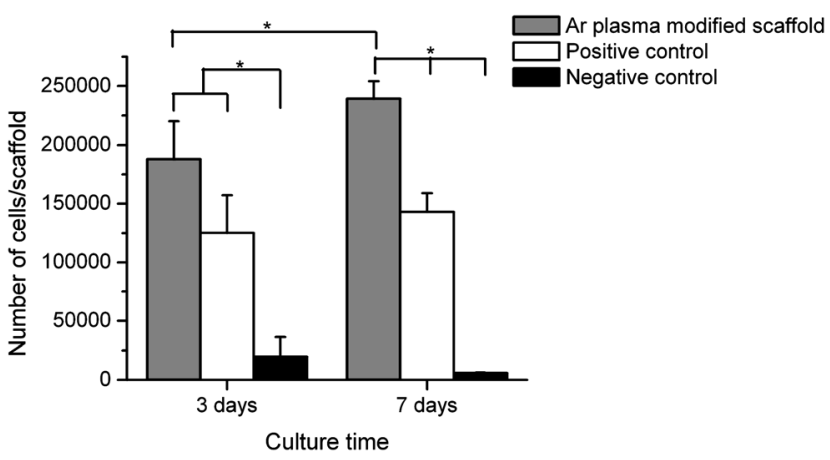

Fig. 8 Cell proliferation of HUVEC growing on plasma-modified scaffold, positive and negative control. The number of cells was determined by DNA quantification. Error bars represent means \pm SD *Significantly different $t$-Test, $p<0.05$. the proliferation rate on plasma-treated scaffolds was significantly higher as compared to the positive control.

\subsection{Expression of endothelial markers}

To confirm the maintenance of the endothelial phenotype and of markers involved in angiogenesis, total RNA was extracted from EC-seeded scaffolds and assayed by RT-PCR. The expression of important cell adhesion molecules such as PECAM-1 and VEcadherin was retained in both plasma-treated and positive control scaffolds (Fig. 9). Furthermore, RT-PCR revealed the expression of the receptor for the most potent angiogenic growth factor, vascular endothelial growth factor (VEGF-R1). On TCP, the optimal surface for tissue culture, used as 2D control, ECs were also capable of producing mRNA that encodes for the three markers under study.

PECAM-1 expression was also assessed at the single-cell level by immunocytochemistry. This marker was depicted as a welldefined green ring around neighbouring cells on the surface of plasma-treated and on positive control SPCL fiber-mesh scaffolds (Fig. 10). In fact, the expression of this adhesion molecule involved in endothelial cell-cell interaction was similar for these two materials and represents the distribution pattern for physiologically quiescent, that is, non-activated ECs.

\section{Discussion}

In a simplistic way, bone can be described as a three-component tissue: (i) a mineralized matrix, supplied by (ii) a complex vascular network and orchestrated by (iii) several cell types that release a multitude of growth factors. Therefore, in a strategy aimed at regeneration of bone tissue, these components must be considered. The bulk structure of the scaffold must take into account the mechanical function of the tissue, while the architecture must allow the penetration of a functional vascular plexus and the scaffold's surface must be compatible with the

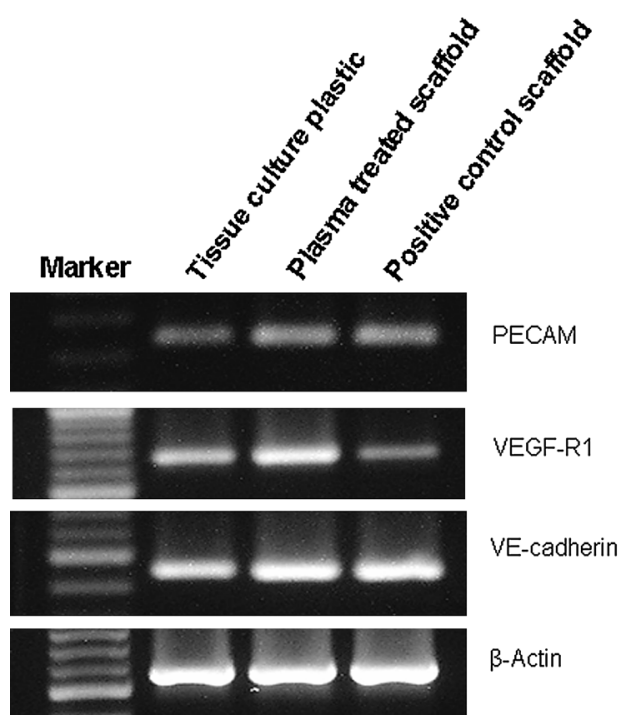

Fig. 9 Expression of endothelial markers at the mRNA level (RT-PCR) for HUVEC grown on tissue culture polystyrene, plasma-treated, and fibronectin-coated SPCL scaffolds. 

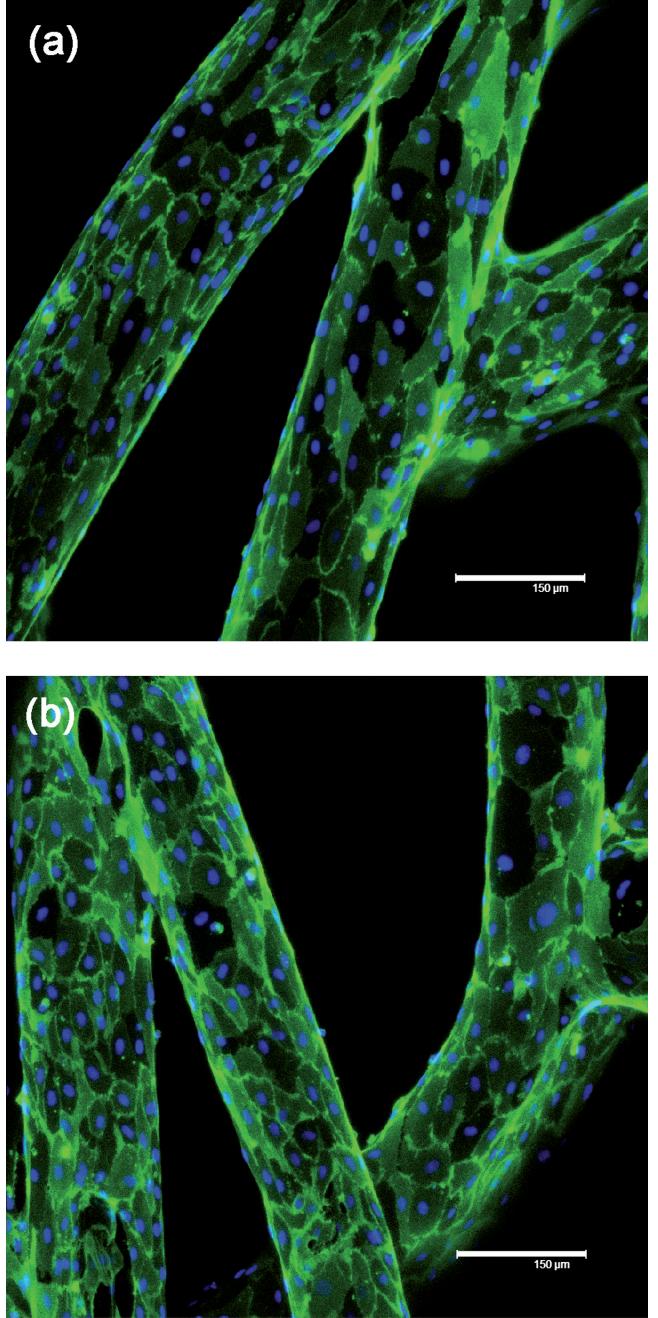

Fig. 10 PECAM-1 staining (green fluorescence) of ECs on plasmamodified SPCL scaffold (a) and on positive control (b) cultured for 7 days. Nuclei were counterstained with Hoechst (blue fluorescence). The value of the scale bars is $150 \mu \mathrm{m}$.

different cells that build up the tissue. SPCL fiber-mesh structures have been proposed as a scaffolding material for bone tissue engineering. ${ }^{21,22,32}$ Previous studies have shown the ability of these scaffolds to promote adhesion of bone marrow cells, their differentiation into an osteoblast lineage accompanied by the deposition of a mineralized matrix and production of several growth factors involved in osteogenesis and angiogenesis. ${ }^{21,23,33}$ Moreover, regarding the importance of ECs in angiogenesis, other work from our group demonstrates the ability of this material to support the adhesion, proliferation and maintenance of the phenotypic expression of ECs. ${ }^{24}$ The surface of SPCL fiber-mesh scaffold requires a pre-coating with an adhesive protein in order to sustain EC adhesion similar to that observed by a large number of other polymeric substrates ${ }^{34-36}$ However, protein adsorption is a process difficult to control and several obstacles such as low stability to sterilization processes, heat treatment and $\mathrm{pH}$ variation, storage and conformation shifting ${ }^{37,38}$ are associated with its application. Therefore, based on the results of our studies, we propose that plasma surface modification of SPCL fiber-mesh scaffolds can be used as an alternative approach to render the surface compatible for EC adhesion. The described methodology has the advantage that it obviates the need for protein precoating and can be simultaneously used as a cost-effective method for sterilization.

The interplay between the surface features changed by plasma modification and the adsorption of proteins may subsequently affect cell behaviour via:

(i) Increasing the surface area available for protein adsorption by etching processes, typically ongoing during the plasma treatment;

(ii) Modulation of the surface chemistry, i.e. the physical bonds on the surface/proteins. Although a straightforward relation can not always be established, EC adhesion is often associated with groups such as hydroxyl $(-\mathrm{OH})$ or carboxyl $(-\mathrm{COOH}))^{39,40}$ Furthermore, enhanced EC proliferation and spreading in response to increased oxygen content has also been shown in previous studies ${ }^{41,42}$ on $2 \mathrm{D}$ samples prepared from synthetic polymers.

(iii) Alternation of the surface charge. Negatively charged groups have shown ${ }^{43-46}$ positive effects on cell adhesion and growth and this is attributed to the favourable protein conformation on these surfaces. The polarity of these groups allows formation of additional hydrogen bonds with the proteins, which will keep them fixed onto the surface. From the oxygen containing functional groups, $\mathrm{COOH}$ are the ones that influence mostly the growth of $\mathrm{ECs}^{47,48}$

When physical plasma comes into contact with the biomaterial surface, the activated species are accelerated towards the substrate by the applied electrical field. Since some parts of the surfaces are exposed to energies higher than the bonding energy of polymers, these parts undergo chain scission. ${ }^{49,50}$ Chain scission processes will then initiate various events. Surface degradation or so-called etching is one of the effects that can be observed. This effect depends on the used power, which determines the acceleration of the active species towards the material surface, as well as on the time during which the material is exposed to this bombarding with active species. Surface etching was observed at the used conditions for SPCL fiber-mesh scaffolds. Both roughness and topography were altered by the applied treatment as shown by optical profilometry. Hence, alterations in cellular/protein behaviour could be expected as a response to the introduced changes of the surface morphology. The higher roughness is associated with a higher surface area and therefore an increased quantity of adsorbed proteins as well as a higher number of cells on the modified surface must be observed. On the other hand, the chain scission was confirmed by TOF-SIMS, where the intensity of the characteristic polymer peaks decreased for the plasma treated material. Chain scission results in the formation of highly reactive radicals on the surface. Those radicals can recombine (e.g. crosslinking reactions) or react with the other species such as oxygen from the air. Those processes were confirmed by both XPS and TOF-SIMS analyses of the surface chemical composition of the studied materials. XPS showed higher oxygen concentration for the modified materials. Additionally, the negative mass spectrum of plasma treated scaffolds was abundant in new, low intensity peaks, which also reveal ongoing functionalisation. Changing of the surface chemistry in turn is expected to modulate protein 
adsorption. Depending on the nature of the established proteinsurface interactions, surfaces can modulate adhesion and cell biochemical mechanisms such as those involved in cell differentiation. Protein-containing solutions can be used as a source of biomolecules that will further bridge and affect cell adhesion. The analysis of the adsorption of the cell-adhesive molecules, Fn and $\mathrm{Vn}$, showed some differences in their comparative adsorption ability as well for the comparison of modified and untreated samples. Although a different affinity of Fn and Vn to 2dimensional SPCL surfaces was previously observed, ${ }^{31}$ the analysis of the adsorption of these molecules on 3D starch-based scaffolds following argon surface modification has not been demonstrated. An important result of the present study is the indication that Vn distribution follows the surface morphology of the studied fibers and can be altered by changing of their surface pattern. Before treatment, a laminated distribution of Fn was observed. This same morphology was also shown by optical profiler for the untreated scaffolds. After plasma treatment the laminated structure was lost and in turn the Vn distribution pattern was affected, analogous to the changed morphology of SPCL scaffolds. $\mathrm{Vn}$ is a biomolecule known to control and modulate EC spreading and migration and is well-characterized as a modulator of the cytoskeleton. ${ }^{51,52}$ On the other hand, no difference was observed for Fn. However, this is not surprising, as it is reported that in complex protein solutions Fn interacts with the available cell non-adhesive molecules, ${ }^{53}$ which reduces its competitiveness and explains its failure to adsorb on to the substrate in the presence of other serum proteins. ${ }^{54} \mathrm{As}$ a result, in bovine plasma and fresh serum higher cell activity is associated with Vn but not with Fn.

Cell adhesion is the ultimate functional result of both the material's surface physicochemical properties and its protein adsorption. The changed physicochemical properties of the underlying substrate can modulate the EC behaviour by affecting the proteins' conformation and orientation and hence enhancing the anchorage strength to the substrate. Additionally, the surface properties of treated scaffolds might also stabilize the proteins secreted and deposited by ECs aimed to constitute the basement membrane. ${ }^{48,55}$ In vitro studies with human ECs revealed that uncoated and non-modified SPCL fiber-mesh scaffolds displayed substantially reduced cellular adhesion. However, cell attachment to SPCL scaffolds was significantly enhanced when physically adsorbed fibronectin, a standard procedure in endothelial culture, was used. Moreover, ECs on the positive controls remained viable and also proliferated during the 7 days of culture. When the SPCL surface was treated by Ar plasma the surface was tailored for EC adhesion, obviating the need for protein pre-coating. Furthermore, the proliferation level of ECs on Ar plasma-treated scaffolds was significantly higher than on the positive control. Hence, plasma treatment not only promoted the initial stages of cell attachment but also triggered the EC metabolic activity.

Protein-mediated interactions established between cells and substrate not only provide anchorage sites for cell adhesion but also dictate important cell parameters such as morphology, proliferation, migration, differentiation and responsiveness. ${ }^{56}$ Therefore, the effect of the performed modification on the morphology and phenotypic/genotypic expression of ECs was assessed. Morphology mirrors cell-substrate interactions in so far as altered orientation of adsorbed proteins will modulate cellular integrin receptor binding and consequently this will be reflected in cytoskeletal re-arrangement. Changing the surface of SPCL fiber-mesh scaffolds by Ar plasma did not affect the typical flattened EC morphology. This is a positive indicator of cellular mechanical coupling to the underlying substrate. Regarding endothelial markers, the expression of VEFGR-1 at the gene level was confirmed for plasma-treated scaffolds as well as on positive and TCP controls. VEGFR-1 is a key gene not only involved in angiogenesis but also associated with monocyte chemotaxis and with recruitment of bone marrow-derived progenitor cells. ${ }^{57}$ Another gene whose expression was maintained on the modified scaffold was VE-cadherin, an essential cell adhesion molecule in establishing and maintaining endothelial integrity. The anchorage of cadherins to the cytoskeleton and their clustering are indispensable for the development of strong and rigid cell-cell adhesions. ${ }^{58}$ Additionally, PECAM-1, one of the hallmarks of the endothelium is a crucial molecule for homotypic adhesion involved in the maintenance of endothelial integrity. ${ }^{59}$ The expression of PECAM-1 was observed on plasma-modified and fibronectin-coated scaffolds at both mRNA and single-cell protein level. Furthermore, cell-cell adhesion was detected at the cell borders, which is a good indication of the non-activated status of interactions between neighbouring cells. These overall results indicate that ECs maintained their differentiated phenotype and the integrity of endothelial monolayer on plasma-modified scaffolds.

\section{Conclusions}

Argon plasma treatment was shown to be an effective method to modify the surface of a 3D starch-based scaffold for EC adhesion. Cell attachment and expression of endothelial markers on plasma-treated SPCL fiber-mesh scaffolds was comparable to the scaffold pre-coated with fibronectin, used as a positive control. However, higher proliferation rates were observed on plasmamodified scaffolds. This improved overall biological outcome is the result of novel protein-surface interactions generated by plasma treatment. Increased surface roughness, altered surface pattern and changed surface chemistry were the main physicochemical changes demonstrated on the SPCL fiber-mesh scaffold surface. Consequently, these properties modulate protein adsorption as indicated by the different adsorption profile of the adhesive protein vitronectin.

Finally, argon plasma treatment renders the surface compatible for ECs and this is a significant step forward towards the improvement of constructs for vascularization. Furthermore, in addition to eliminating the need for pre-coating with proteins and the respective drawbacks associated with this methodology, plasma treatment does not affect the scaffold's bulk structure and can simultaneously be used as an effective sterilization method. Starch-based scaffolds treated by Ar plasma were shown to be a good support to use on bone tissue engineering, where vascularization is a main requirement.

\section{Acknowledgements}

M.I. Santos would like to acknowledge the Portuguese Foundation for Science and Technology (FCT) for her PhD grant 
(SFRH/BD/13428/2003). This work was partially supported by FCT through funds from POCTI and/or FEDER programs and by the European Union funded STREP Project HIPPOCRATES (NMP3-CT-2003-505758). This work was carried out under the scope of the European NoE EXPERTISSUES (NMP3-CT-2004500283).

The authors would also like to acknowledge A. Sartoris and B. Malenica for their excellent technical assistance and C. Serra (CACTI, Vigo, Spain) for the helpful discussion of ToF-SIMS results.

\section{References}

1 D. O. Fauza, Tissue engineering: Current state of clinical application, Current Opinion in Pediatrics, 2003, 15(3), 267-271.

2 U. Kneser, D. J. Schaefer, E. Polykandriotis and R. E. Horch, Tissue engineering of bone: the reconstructive surgeon's point of view, Journal of Cellular and Molecular Medicine, 2006, 10(1), 7-19.

3 G. F. Muschler, C. Nakamoto and L. G. Griffith, Engineering principles of clinical cell-based tissue engineering, J. Bone Joint Surg. Am., 2004, 86-A(7), 1541-58.

4 I. McCarthy, The physiology of bone blood flow: a review, J. Bone Joint Surg. Am., 2006, 88(Suppl. 3), 4-9.

5 P. H. Warnke, I. N. Springer, J. Wiltfang, Y. Acil, H. Eufinger, M. Wehmoller, P. A. Russo, H. Bolte, E. Sherry, E. Behrens and H. Terheyden, Growth and transplantation of a custom vascularised bone graft in a man, Lancet, 2004, 364(9436), 766-70.

6 U. Kneser, E. Polykandriotis, J. Ohnolz, K. Heidner, L. Grabinger, S. Euler, K. U. Amann, A. Hess, K. Brune, P. Greil, M. Sturzl and R. E. Horch, Engineering of vascularized transplantable bone tissues: induction of axial vascularization in an osteoconductive matrix using an arteriovenous loop, Tissue Eng., 2006, 12(7), 1721-31.

7 O. C. Cassell, S. O. Hofer, W. A. Morrison and K. R. Knight, Vascularisation of tissue-engineered grafts: the regulation of angiogenesis in reconstructive surgery and in disease states, $\mathrm{Br} . \mathrm{J}$. Plast. Surg., 2002, 55(8), 603-10.

8 Z. S. Patel and A. G. Mikos, Angiogenesis with biomaterial-based drug- and cell-delivery systems, J. Biomater. Sci. Polym. Ed., 2004, 15(6), 701-26.

9 H. Yamashita, A. Shimizu, M. Kato, H. Nishitoh, H. Ichijo, A. Hanyu, I. Morita, M. Kimura, F. Makishima and K. Miyazono, Growth/differentiation factor-5 induces angiogenesis in vivo, Experimental Cell Research, 1997, 235(1), 218-226.

10 R. R. Chen, E. A. Silva, W. W. Yuen and D. J. Mooney, Spatiotemporal VEGF and PDGF delivery patterns blood vessel formation and maturation, Pharmaceutical Research, 2007, 24(2), 258-264.

11 N. I. Moldovan and M. Ferrari, Prospects for microtechnology and nanotechnology in bioengineering of replacement microvessels, Arch. Pathol. Lab. Med., 2002, 126(3), 320-4.

$12 \mathrm{H}$. Masuda and T. Asahara, Post-natal endothelial progenitor cells for neovascularization in tissue regeneration, Cardiovasc. Res., 2003, 58(2), 390-8.

13 R. E. Unger, A. Sartoris, K. Peters, A. Motta, C. Migliaresi, M. Kunkel, U. Bulnheim, J. Rychly and C. J. Kirkpatrick, Tissuelike self-assembly in cocultures of endothelial cells and osteoblasts and the formation of microcapillary-like structures on threedimensional porous biomaterials, Biomaterials, 2007, 28(27), 396576.

14 P. K. Chu, J. Y. Chen, L. P. Wang and N. Huang, Plasma-surface modification of biomaterials, Materials Science \& Engineering $R$ Reports, 2002, 36(5-6), 143-206.

15 X. Liu and P. X. Ma, Polymeric scaffolds for bone tissue engineering, Ann. Biomed. Eng., 2004, 32(3), 477-86.

16 T. Douglas, U. Hempel, C. Mietrach, S. Heinemann, D. Scharnweber and $\mathrm{H}$. Worch, Fibrils of different collagen types containing immobilised proteoglycans (PGs) as coatings: characterisation and influence on osteoblast behaviour, Biomol. Eng., 2007, 24(5), 455-8.

17 R. S. Bhati, D. P. Mukherjee, K. J. McCarthy, S. H. Rogers, D. F. Smith and S. W. Shalaby, The growth of chondrocytes into a fibronectin-coated biodegradable scaffold, J. Biomed. Mater. Res., 2001, 56(1), 74-82.
18 S. P. Massia and J. A. Hubbell, Human endothelial cell interactions with surface-coupled adhesion peptides on a nonadhesive glass substrate and two polymeric biomaterials, J. Biomed. Mater. Res., 1991, 25(2), 223-42.

19 H. Chim, J. L. Ong, J. T. Schantz, D. W. Hutmacher and C. M. Agrawal, Efficacy of glow discharge gas plasma treatment as a surface modification process for three-dimensional poly (D,L-lactide) scaffolds, J. Biomed. Mater. Res., 2003, 65A(3), 327-335.

20 J. Lin, M. L. Lindsey, B. Zhu, C. M. Agrawal and S. R. Bailey, Effects of surface-modified scaffolds on the growth and differentiation of mouse adipose-derived stromal cells, J. Tissue Eng. Regen. Med., 2007, 1(3), 211-7.

21 M. E. Gomes, V. I. Sikavitsas, E. Behravesh, R. L. Reis and A. G. Mikos, Effect of flow perfusion on the osteogenic differentiation of bone marrow stromal cells cultured on starchbased three-dimensional scaffolds, J. Biomed. Mater. Res., 2003, 67A(1), 87-95.

22 M. P. Pavlov, J. F. Mano, N. M. Neves and R. L. Reis, Fibers and 3D mesh scaffolds from biodegradable starch-based blends: production and characterization, Macromol. Biosci., 2004, 4(8), 776-84.

23 M. E. Gomes, H. L. Holtorf, R. L. Reis and A. G. Mikos, Influence of the porosity of starch-based fiber mesh scaffolds on the proliferation and osteogenic differentiation of bone marrow stromal cells cultured in a flow perfusion bioreactor, Tissue Eng., 2006, 12(4), 801-9.

24 M. I. Santos, S. Fuchs, M. E. Gomes, R. E. Unger, R. L. Reis and C. J. Kirkpatrick, Response of micro- and macrovascular endothelial cells to starch-based fiber meshes for bone tissue engineering, Biomaterials, 2007, 28(2), 240-8.

25 M. E. Gomes, H. S. Azevedo, A. R. Moreira, V. Ella, M. Kellomaki and R. L. Reis, Starch-poly(epsilon-caprolactone) and starchpoly(lactic acid) fibre-mesh scaffolds for bone tissue engineering applications: structure, mechanical properties and degradation behaviour, J. Tissue Eng. Regen. Med., 2008, 2(5), 243-52.

26 V. Marin, G. Kaplanski, S. Gres, C. Farnarier and P. Bongrand, Endothelial cell culture: protocol to obtain and cultivate human umbilical endothelial cells, Journal of Immunological Methods, 2001, 254(1-2), 183-190.

27 G. Punshon, D. S. Vara, K. M. Sales, A. G. Kidane, H. J. Salacinski and A. M. Seifalian, Interactions between endothelial cells and a poly(carbonate-silsesquioxane-bridge-urea) urethane, Biomaterials, 2005, 26(32), 6271-6279.

28 R. Ogaki, F. M. Green, S. L. M. Vert, M. R. Alexander, I. S. Gilmore and M. C. Davies, A comparison of the static SIMS and G-SIMS spectra of biodegradable homo-polyesters, Surface and Interface Analysis, 2008, 40(8), 1202-1208.

29 A. Adriaens, L. Van Vaeck and F. Adams, Static secondary ion mass spectrometry (S-SIMS) Part 2: Material science applications, Mass Spectrometry Reviews, 1999, 18(1), 48-81.

30 A. B. D. Cassie and S. Baxter, Wettability of porous surfaces, Transactions of the Faraday Society, 1944, 40, 0546-0550.

31 C. M. Alves, R. L. Reis and J. A. Hunt, Preliminary study on human protein adsorption and leukocyte adhesion to starch-based biomaterials, J. Mater. Sci. Mater. Med., 2003, 14(2), 157-65.

32 A. L. Oliveira and R. L. Reis, Pre-mineralisation of starch/ polycrapolactone bone tissue engineering scaffolds by a calciumsilicate-based process, J. Mater. Sci. Mater. Med., 2004, 15(4), 53340.

33 M. E. Gomes, C. M. Bossano, C. M. Johnston, R. L. Reis and A. G. Mikos, In vitro localization of bone growth factors in constructs of biodegradable scaffolds seeded with marrow stromal cells and cultured in a flow perfusion bioreactor, Tissue Eng., 2006, 12(1), 177-88.

34 R. E. Unger, K. Peters, M. Wolf, A. Motta, C. Migliaresi and C. J. Kirkpatrick, Endothelialization of a non-woven silk fibroin net for use in tissue engineering: growth and gene regulation of human endothelial cells, Biomaterials, 2004, 25(21), 5137-5146.

35 T. Pompe, K. Keller, G. Mothes, M. Nitschke, M. Teese, R. Zimmermann and C. Werner, Surface modification of poly(hydroxybutyrate) films to control cell-matrix adhesion, Biomaterials, 2007, 28(1), 28-37.

36 S. L. Sanborn, G. Murugesan, R. E. Marchant and K. KottkeMarchant, Endothelial cell formation of focal adhesions on hydrophilic plasma polymers, Biomaterials, 2002, 23(1), 1-8. 
37 U. Hersel, C. Dahmen and H. Kessler, RGD modified polymers: biomaterials for stimulated cell adhesion and beyond, Biomaterials, 2003, 24(24), 4385-415.

38 C. M. Alves, Y. Yang, D. L. Carnesc, J. L. Ong, V. L. Sylvia, D. D. Dean, C. M. Agrawal and R. L. Reis, Modulating bone cells response onto starch-based biomaterials by surface plasma treatment and protein adsorption, Biomaterials, 2007, 28, 307 315

39 T. G. Ruardy, H. E. Moorlag, J. M. Schakenraad, H. C. VanderMei and H. J. Busscher, Growth of fibroblasts and endothelial cells on wettability gradient surfaces, J. Colloid Interface Sci., 1997, 188(1), 209-217.

40 K. KottkeMarchant, A. A. Veenstra and R. E. Marchant, Human endothelial cell growth and coagulant function varies with respect to interfacial properties of polymeric substrates, J. Biomed. Mater Res., 1996, 30(2), 209-220.

41 S. Tajima, J. S. Chu, S. Li and K. Komvopoulos, Differential regulation of endothelial cell adhesion, spreading, and cytoskeleton on low-density polyethylene by nanotopography and surface chemistry modification induced by argon plasma treatment, $J$ Biomed. Mater. Res., 2007, 84A(3), 828-836.

42 S. I. Ertel, B. D. Ratner and T. A. Horbett, Radiofrequency plasma deposition of oxygen-containing films on polystyrene and poly(ethylene terephthalate) substrates improves endothelial cell growth, J. Biomed. Mater. Res., 1990, 24(12), 1637-59.

43 M. H. Lee, P. Ducheyne, L. Lynch, D. Boettiger and R. J. Composto, Effect of biomaterial surface properties on fibronectin-alpha5betal integrin interaction and cellular attachment, Biomaterials, 2006, 27(9), 1907-16

44 B. G. Keselowsky, D. M. Collard and A. J. Garcia, Surface chemistry modulates fibronectin conformation and directs integrin binding and specificity to control cell adhesion, J. Biomed. Mater. Res., 2003, 66A(A), 247-59.

45 B. G. Keselowsky, D. M. Collard and A. J. Garcia, Surface chemistry modulates focal adhesion composition and signaling through changes in integrin binding, Biomaterials, 2004, 25(28), 5947-54.

46 N. Faucheux, R. Tzoneva, M. D. Nagel and T. Groth, The dependence of fibrillar adhesions in human fibroblasts on substratum chemistry, Biomaterials, 2006, 27(2), 234 45.

47 Y. X. Wang, J. L. Robertson, W. B. Spillman, Jr. and R. O. Claus, Effects of the chemical structure and the surface properties of polymeric biomaterials on their biocompatibility, Pharm. Res., 2004, 21(8), 1362-73.

48 C. D. Tidwell, S. I. Ertel, B. D. Ratner, B. J. Tarasevich, S. Atre and D. L. Allara, Endothelial cell growth and protein adsorption on terminally functionalized, self-assembled monolayers of alkanethiolates on gold, Langmuir, 1997, 13(13), 3404-3413.

49 N. Inagaki, Plasma surface modification and plasma polymerization. Technomic Publishing AG: Basel, Switzerland, 1996.

50 C. Oehr, Plasma surface modification of polymers for biomedical use, NIM B, 2003, 208, 40-47.

51 M. A. Schwartz, Spreading of human endothelial cells on fibronectin or vitronectin triggers elevation of intracellular free calcium, J. Cell Biol., 1993, 120(4), 1003-10.

52 D. I. Leavesley, M. A. Schwartz, M. Rosenfeld and D. A. Cheresh, Integrin beta 1 - and beta 3 -mediated endothelial cell migration is triggered through distinct signaling mechanisms, J. Cell Biol., 1993, 121(1), 163-70.

53 P. B. v. Wachem, B. W. L. Mallens, A. Dekker, T. Beugeling, J. Feijen, A. Bantjes, J. P. Detmers and W. G. v. Aken, Adsorption of fibronectin derived from serum and from human endothelial cells onto tissue culture polystyrene, J. Biomed. Mater. Res., 1987, 21(11), 1317-1327.

54 P. A. Underwood and F. A. Bennett, A comparison of the biological activities of the cell-adhesive proteins vitronectin and fibronectin, $J$. Cell Sci., 1989, 93(Pt 4), 641-9.

55 C. F. L. Chu, A. Lu, M. Liszkowski and R. Sipehia, Enhanced growth of animal and human endothelial cells on biodegradable polymers, Biochimica Et Biophysica Acta-General Subjects, 1999, 1472(3), 479485

56 P. F. Davies, A. Robotewskyj and M. L. Griem, Endothelial cell adhesion in real time. Measurements in vitro by tandem scanning confocal image analysis, J. Clin. Invest., 1993, 91(6), 2640-52.

57 H. Roy, S. Bhardwaj and S. Yla-Herttuala, Biology of vascular endothelial growth factors, Febs Letters, 2006, 580(12), 2879-2887.

58 R. Tzoneva, N. Faucheux and T. Groth, Wettability of substrata controls cell-substrate and cell-cell adhesions, Biochimica et Biophysica Acta (BBA) - General Subjects, 2007, 1770(11), 1538-1547.

59 F. R. Pu, R. L. Williams, T. K. Markkula and J. A. Hunt, Effects of plasma treated PET and PTFE on expression of adhesion molecules by human endothelial cells in vitro., Biomaterials, 2002, 23(11), $2411-28$ 